\title{
Research on Facilities of Power Supply of Small Power Capability Consumers of Bukhara Region by using Wind and Solar Energy
}

\author{
Sadullayev Nasillo Nematovich, Safarov Alisher Bekmurodovich, Nematov Shuhrat \\ Nasilloyevich, Mamedov Rasul Akif-ogli
}

\begin{abstract}
This article analyzes the climatic features of the Bukhara region - the southern-eastern part of Uzbekistan. The wind and solar potential of the region and the prospects of its utilization were evaluated. In recent years, wind and solar energy has been analyzed worldwide. The potential for the use of solar radiation in the region was analyzed. Accordingly, when the solar photovoltaic batteries in the region are used (coefficient of efficiency-18\%), the technical potential of the region is 41 TWh/year. Wind speeds and wind energy potential data were collected over eight years (2011-2018) and were calculated using the monthly wind speed data measured every 30 minutes at a height of $10 \mathrm{~m}$. During the estimation of wind energy potential we were used two parameters Weibull and Rayleigh distribution functions. The density power and energy values of the wind flow at various heights were evaluated using the extrapolation method. In accordance with that, on height of $10 \mathrm{~m}$ it makes 41.19 $\mathrm{W} / \mathrm{m} 2$ and $361.48 \mathrm{kWh} / \mathrm{m} 2$, on height of $50 \mathrm{~m} 117.23 \mathrm{~W} / \mathrm{m} 2$ $1026.96 \mathrm{kWh} / \mathrm{m} 2$, and on height of $100 \mathrm{~m} 192.76 \mathrm{~W} / \mathrm{m} 2,1688.59$ $k W h / m 2$. The wind energy gross, technical and economic potential of the region has been evaluated. In addition, the potential and prospects of using hybrid (wind and solar) power stations for the supply of uninterrupted and reliable power supply to consumers in the region were analyzed.
\end{abstract}

Keywords: solar energy potential, wind energy potential, Weibull distribution function, Rayleigh distribution function, wind direction (wind rose), extrapolation method, hybrid (wind and solar) power station.

\section{INTRODUCTION}

Nowadays, the demand for energy is rising as the population is growing. Production of non-renewable energy sources has reached a high level in meeting human needs. As a result, climate change has adverse consequences. According to statistics, Uzbekistan is ranked 7th in the world by pollution level in 2018 [1]. The main reason for this is that more than $87 \%$ of the generated electricity is in the share of hydrocarbon raw materials. In order to reduce this trend, it is necessary to increase the use of renewable energy sources, i.e. green energy in the region.

In Central Asia, renewable energy sources are rapidly developing with the use of solar, wind, biomass, geothermal and water energy [2]. Because of the low cost of electricity generated on renewable energy sources and is almost no environmental, these projects are widely used in practice, they are invested in large amounts, and promising

Revised Manuscript Received on July 18, 2019.

Sadullayev Nasillo Nematovich, Professor, Department of Energy audit, Bukhara Engineering Technological Institute, Bukhara, Uzbekistan

Safarov Alisher Bekmurodovich, Ph.D. Students Department of Energy audit, Bukhara Engineering Technological Institute, Bukhara, Uzbekistan

Nematov Shuhrat Nasilloyevich, Ph.D. Students Department of Energy audit, Bukhara Engineering Technological Institute, Bukhara, Uzbekistan

Mamedov Rasul Akif-ogli, Ph.D. Students Department of Energy audit, Bukhara Engineering Technological Institute, Bukhara, Uzbekistan

development and research is supported. Many types of alternative energy sources are being studied to generate more energy flows in energy systems. The use of alternative sources of energy in power supply will have a great impact on increasing the reliability of electricity supply[3].

Diversification of energy sources based on renewable sources allows saving energy resources, improving the reliability of electricity supply to consumers and improving the environment. Another prospective direction in the development of the electric power system is the creation of "smart" networks, one of the tasks of which is to diversify the energy sources of power grid units. This circumstance determines the relevance of research to create efficient alternative energy sources based on renewable types of energy.

Low-power consumers in rural areas are small enterprises for the production of building materials, processing of agricultural products, services, educational institutions, community facilities, etc. The main problem of these facilities is power outages and the inability to expand production due to lack of power sources of energy. This question is particularly relevant for farms located in remote locations from the power grid. An effective solution to improve energy efficiency and reliability of power supply is to diversify the source of electricity, i.e. introduction of "hybrid" energy sources, consisting of several alternative sources.

The climatic conditions of the Republic of Uzbekistan do not allow the effective use of wind power plants. Due to the weak and unstable flow of energy from these sources, the resulting alternating current electric power at the generator output becomes impossible to use. Therefore, this energy is usually used through accumulation in the form of direct current energy, and then in the form of variable with the help of inverters, which leads to higher costs and a decrease in the efficiency of these installations. The efficiency of these machines can be improved with the use of wind power plants (WPP) with a vertical axis of rotation, as well as more rational planning of operating modes of these sources, i.e. generate electricity only after the accumulation of energy from renewable sources. The accumulated energy is consumed by a strong and constant flow, which ensures the generation of alternating current with a constant frequency and voltage amplitude. This eliminates the use of accumulators and inverters, respectively, increases the efficiency of these sources. 


\section{RESEARCH ON FACILITIES OF POWER SUPPLY OF SMALL POWER CAPABILITY CONSUMERS OF BUKHARA REGION BY USING WIND AND SOLAR ENERGY}

\section{REVIEW OF THE LITERATURE}

S.V. Kiseleva, Yu.G. Kolomiets, O.S. Popel the potential and benefits of solar energy in Central Asian countries are assessed. In these countries, the annual energy of solar light and their gross and technical potential have been assessed and analyzed [4].

R.A. Zakhidov, M.V. Kremkov this article provides information on the potential of wind energy in Uzbekistan, the potential for technical capacities and the use of wind energy [5].

J.N Touafio, S. Melenguiza and others. The wind energy potential of the Bangui region in central Africa, using WAsP software and the Veybull distribution function were studied and estimated. Wide range of wind energy potential assessment techniques at different levels is highlighted. The wind rose repetition graph for Bangui was built and analyzed [6].

B. Eshchanov, A. Abulkasimova and others. The potential of renewable energy sources in the Central Asian states (Uzbekistan, Tajikistan, Kyrgyzstan, Turkmenistan, Kazakhstan) is described in greater detail about their potential and prospects [7].

B.N Prashanth, R.Pramod, G.B Veeresh Kumar, this article explains the features, advantages and disadvantages of using hybrid (solar, wind) power plants in the supply of small consumers with continuous and durable electricity [8].

\section{METHODOLOGY \& RESULTS}

\subsection{Assessment Methods Of Potential Of Wind Energy}

The speed of the wind is variable and can change its speed and direction several times a day. It is impossible to estimate the potential for wind energy by calculating the monthly average wind speed of the meteorological station. At present, world experience has shown that the use of the Weibull and Rayleigh distribution functions in the static analysis of wind energy potential will be effective in making reliable estimates of the wind speed properties and energy potential [9].

In determining the speed of the wind, we need to determine the experimental (wind speed repeatability) and density functions of the Weibull distribution. These expressions are defined as follows [10]:

$$
\begin{array}{cc}
f(v)=\frac{k}{c} \cdot\left(\frac{\bar{v}}{c}\right)^{k-1} \cdot e^{-\left(\frac{\bar{v}}{c}\right)^{k}} & 0 \leq \bar{v} \leq \infty \\
F(v)=\int_{0}^{\infty} f(\bar{v}) d \bar{v}=1-e^{-\left(\frac{\bar{v}}{c}\right)^{k}} & 1 \leq k \leq 10
\end{array}
$$

Where: $\mathrm{k}$ - the shape factor (depending on location); c- The parameter that determines the extent of the function distribution (parameter, depending on the average wind speed $\mathrm{m} / \mathrm{s}$ ).

When shape parameter in the Weibull distribution function $\mathrm{k}=2$, Rayleigh changes to the distribution function. Empire and density functions of the Rayleigh distribution are determined by the following expression[11]:

$$
\begin{aligned}
& f(v)=\frac{2 \bar{v}}{c^{2}} \cdot e^{-\left(\frac{\bar{v}}{c}\right)^{2}} \\
& F(v)=\int_{0}^{\infty} f(\bar{v}) d \bar{v}=1-e^{-\left(\frac{\bar{v}}{c}\right)^{2}}
\end{aligned}
$$

The dependence of $\mathrm{k}$ and $\mathrm{c}$ parameters is shown in the following expression[12,13]:

$$
\begin{aligned}
& k=\left(\frac{\sigma}{\bar{v}}\right)^{-1,086} \\
& c=\frac{G\left(1+\frac{1}{k}\right)}{G(}
\end{aligned}
$$

In the Rayleigh distribution function, $\mathrm{k}=2$, and $\mathrm{c}$ is determined by the following expression:

$$
c=\bar{v} \cdot \frac{2}{\sqrt{\pi}}
$$

The average speed of the wind and the standard deviation are based on the following dependence:

$$
\bar{v}=\frac{1}{N} \cdot \sum_{i=1}^{N} v_{i}
$$

Where: $\mathrm{V}^{-}$- average value of wind speed, $\mathrm{V} \_\mathrm{i}$ - daily rate wind speed, N-number of collected data, G- gamma function.

$$
\sigma=\sqrt{\frac{1}{N-1} \cdot \sum_{i=1}^{N}\left(v_{i}-\bar{v}\right)^{2}}
$$

Specific power and energy values of the wind flow defined through the parameters in the Weibull distribution function are determined by the following expressions $[14,15,16]$ :

$$
\begin{aligned}
& \frac{P_{W}}{A}=\int_{0}^{\infty} \frac{1}{2} \rho v^{3} f(v) d v=\frac{1}{2} \rho c^{3} G\left(1+\frac{3}{k}\right) \\
& \frac{E_{W}}{A}=\int_{0}^{\infty} \frac{1}{2} \rho v^{3} f(v) d v=\frac{1}{2} \rho c^{3} G\left(1+\frac{3}{k}\right) \cdot T
\end{aligned}
$$

Specific power and energy values of the wind flow defined through the parameters in the Rayleigh distribution function are determined by the following expressions[17]:

$$
\begin{aligned}
& \frac{P_{R}}{A}=\frac{3}{\pi} \rho c^{3}\left(\frac{\pi}{4}\right)^{\frac{3}{2}} \\
& \frac{E_{R}}{A}=\frac{3}{\pi} \rho c^{3}\left(\frac{\pi}{4}\right)^{\frac{3}{2}} \cdot T
\end{aligned}
$$

Where: T- time.

\subsection{Extrapolation Method}

The average wind speed mainly changes at different heights are mainly dependent on the density, pressure, temperature and humidity of the airflow. The density of the airflow is so high that it is upward. The expression of airflow density change according to the change in height is as follow[18]:

$$
\rho=\rho_{0}-\left(1,194 \cdot 10^{-4} \cdot H\right)
$$

Where:

$\rho_{0^{-}}$density of airflow in normal conditions $\rho_{0}=1,23 \mathrm{~kg} / \mathrm{m}^{3}$; $\mathrm{H}$ - the height of the wind speed measured.

The wind speed values depend on height high. As the height increases, the wind speed increases. The following formula shows the dependence of the wind speed on height:

$$
v_{2}=v_{1} \cdot\left(\frac{H_{2}}{H_{1}}\right)^{\alpha}
$$


Here: $\mathrm{V}_{2}$ - The wind speed measured at a certain height, $\mathrm{V}_{1^{-}}$Wind speed measured at the initial level, $\mathrm{H}_{1}$ - Station elevation, $\mathrm{H}_{2}$ - Selected height, $\propto$ - Wind shear exponent (for Bukhara region $\propto=0,16$ ).

As the height changes, the values of basic parameters in the Weibull distribution also change. Changes in shape and scale parameters at a certain height in the dependence of height are defined as follows[19]:

$$
\begin{gathered}
k_{H_{2}}=\frac{k_{H 1}}{1-0,0881 \ln \left(\frac{H_{2}}{H_{1}}\right)} \\
C_{H_{2}}=c_{H_{1}}\left(\frac{H_{2}}{H_{1}}\right)^{n} \\
n=\left[0,37-0,0881 \ln \left(c_{H_{1}}\right)\right]
\end{gathered}
$$

\subsection{Gross, Technical And Economic Potential Of Wind Energy}

The gross potential - theoretical value of wind energy that is raised or formed in a particular region. The gross potential is summarized with the following relation $[20,21]$ :

$$
E_{y a}=E_{w} \cdot \frac{S}{20}=\frac{1}{40} \cdot \rho T S \sum_{i=1}^{n} v_{i}^{3} t_{i}
$$

Where: E_w- specific wind energy (Weibull distribution), $\mathrm{T}$ - annual working time of the turbine, $\mathrm{S}$ - area of the region, $\mathrm{v} \_\mathrm{i}$ - average annual wind speed, $\mathrm{t}$ - $\mathrm{i}$ - the possibility to find the wind speed at a certain interval.

\section{Technical potential -}

energy from existing wind turbines, which is part of the gross potential. We estimate the technical capability by means of the following expression:

$$
E_{T}=\frac{N T k S}{100 D^{2}}
$$

Where: $\mathrm{N}$ - nominal power of the wind turbine, $\mathrm{k}$ coefficient of use of power of installed wind turbines, Ddiameter of the wind turbine.

\section{Economical potential -}

the potential of wind power in the region as an annual amount of energy supply by using wind turbines in the region, which is largely consist of the cost of construction, assembly, equipment, transport, energy and fuel at the current level and environmental standards will be evaluated. The economic potential is approximately $0.5 \%$ of the technical potential.

$$
E_{e}=E_{T} \cdot 0,005
$$

\subsection{The Potential Of Solar Energy Of The Region}

The results of the research on the use of solar energy in Uzbekistan are sufficiently enough, and for many years, there are many experimental working examples of such devices. Due to the widespread launch of solar power plants in our country and a significant increase in their number in recent years, there is a growing need for such equipment manufacturers, assemblers, running and service providers and specialists.

Uzbekistan's gross solar energy potential amounts to 50973 million t.n.e, and technical potential is 176.8 million t.n.e. Thus, the fall of solar energy per year in Uzbekistan is much higher than the country's investigated hydrocarbon raw material. At present only $0.3 \%$ of solar energy is used.

Bukhara Region is located in latitude $39.77^{\circ}$ south and $64.48^{\circ}$ west of Uzbekistan, its total area is 39.4 thousand square kilometers. The region consists of $75 \%$ of steppes and deserts. There are more than $90 \%$ of solar energy available in renewable energy sources. Bukhara region is one of the areas with high temperatures. On the basis of the data obtained from the Bukhara International airport meteorological station, we analyze statistical data of climatic conditions, solar radiation, and harrows.

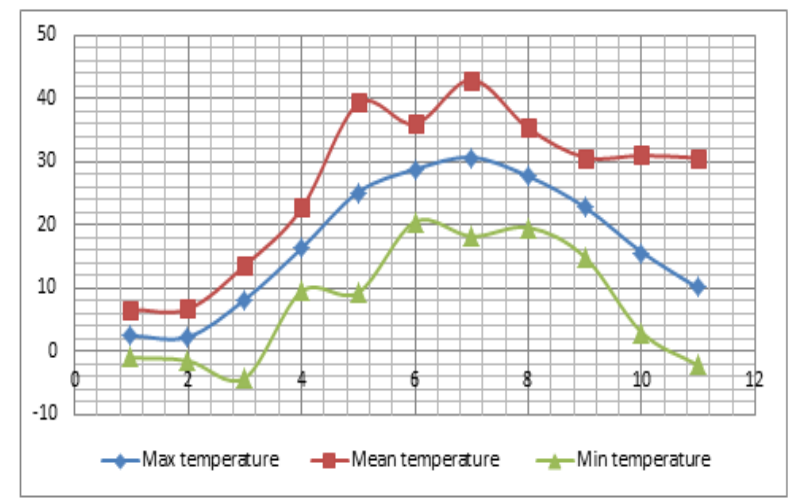

Fig.1. Temperature change in the Bukhara region per months $\left({ }^{\circ} \mathrm{C}\right)$

In this graph, we can see the temperature change diagram in the Bukhara region. Air temperature can reach $30-40{ }^{\circ} \mathrm{C}$ in summer.

\section{Solar potential of area of Bukhara region:}

280-300 the days are sunny day;

Average temperature of $2900 \div 3100$ hours is $+40{ }^{\circ} \mathrm{C}$, day duration makes 12-14 hours;

In desert areas temperature can reach up to $+50{ }^{\circ} \mathrm{C}$;

Solar radiation can reach up to $1800-1900 \mathrm{~kW}$ for each 1 $m$ in year 


\section{RESEARCH ON FACILITIES OF POWER SUPPLY OF SMALL POWER CAPABILITY CONSUMERS OF BUKHARA REGION BY USING WIND AND SOLAR ENERGY}

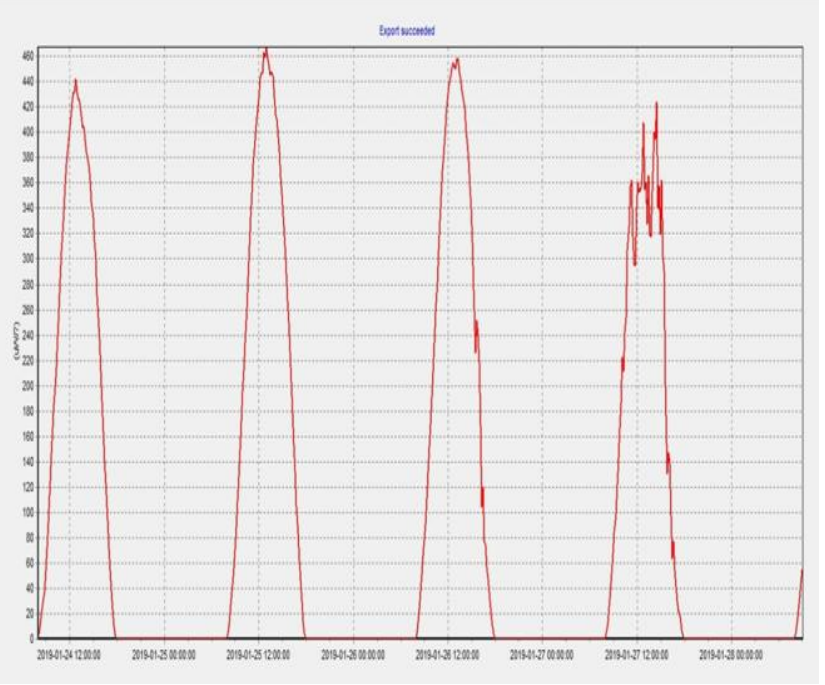

Fig.2. Data of the solar energy comparative power from the meteorological station set up at the Institutional building (January 2019)

In the field of receiving electricity using solar energy, it is important to estimate accurately the potential of solar energy in the region. In this graph, the specific power of solar energy in the Bukhara region is presented. The specific power is power of the sunrays falling on the unit of area of surface.

When we use photovoltaic solar panels (coefficient of efficiency is $18 \%$ ) in the Bukhara region, the technical potential of the region is $41 \mathrm{TWh} /$ year. This means that it is several times higher than the energy used in Bukhara today

We have the potential to obtain $184 \mathrm{TWh} /$ year energy from the solar energy heat of the region, that is, the technical capacity of collectors (coefficient of efficiency is $80 \%$ ). If we used this energy fully, we would have supplied the Bukhara region with full heat and electricity.

3.5. Analysis Of Use Of Hybrid Solar And Wind Power Station In Bukhara Region

Using these energy currents will greatly enhance the reliability of electricity supply to consumers of electricity. Because, either in the area where the energy device is installed, if the value of the solar energy be reduced or absent, for example, at night, the energy shortage can be reduced by using wind and water energy. The more electricity consumed in the power supply, the greater the reliability of the power supply. However, there necessary to take into account the cost of electric power, otherwise the cost of consuming electricity for the consumer will be much more expensive. Therefore, it is necessary to calculate the power supply of each energy source and the consumer power required during the design of the power supply. To carry out these calculations, information on the value of energy flows required for the operation of energy resources is required. We can do this directly by measuring the data or setting up a meteorological station that automatically

Twenty-four-hour automatic measurement of wind parameters have been carried out at a weather station of the MISOL type (fig. 11), installed on the institute's roof at an records data in that area.

altitude of 15 meters. This graph shows solar and wind energy for 2 months. Daily wind energy is calculated, working on a renewable energy source for low-power consumers distant from electrical networks, is proposed.

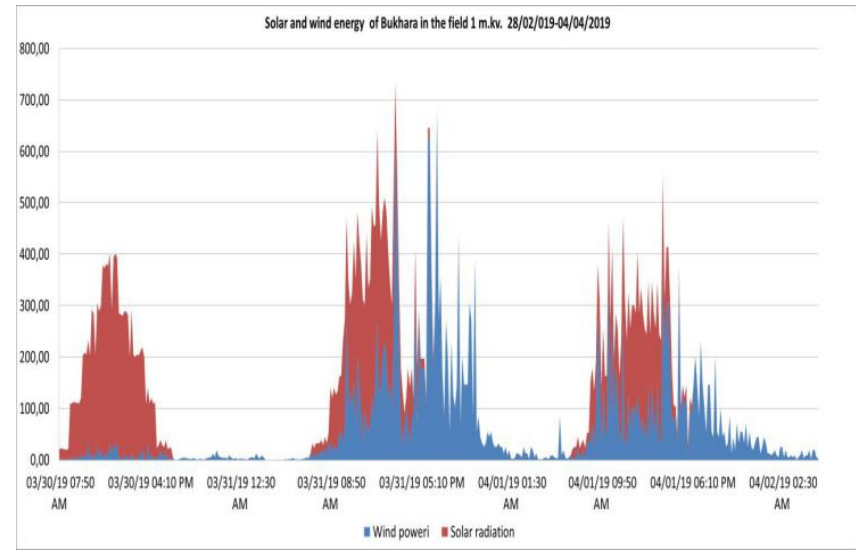

Fig. 3. Solar and wind power density in Bukhara region Uzbekistan, $\mathrm{W} / \mathrm{m}^{2}$

Under such climatic conditions the most effective decision of increase energy efficiency and reliability of electro supply is use of "hybrid" energy sources. A "hybrid" energy source for low-power consumers, consisting of several sources and energy storage devices, working in conjunction with an electrical network has been developed (fig. 3). The source of electricity consists of a WPP with a mechanical drive, a solar panel with an accumulator, an inverter, and a microcontroller for switching sources (Fig. 4). The WPP includes a three-blade wind wheel on a mast with flanges and an axial synchronous low-speed generator with permanent magnets (Fig. 5, b). Vertically oriented wind power station requires a minimum of space for placement, it is absolutely harmless due to the absence of radiation, vibration and noise load.

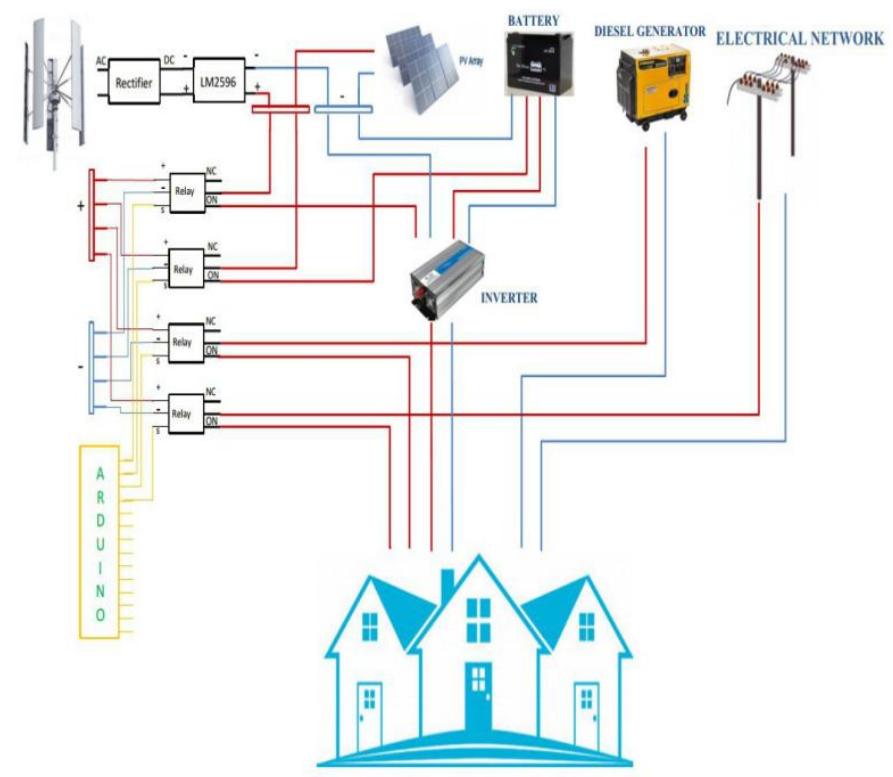

Fig.4. Structure of the "Hybrid" source of electricity. 


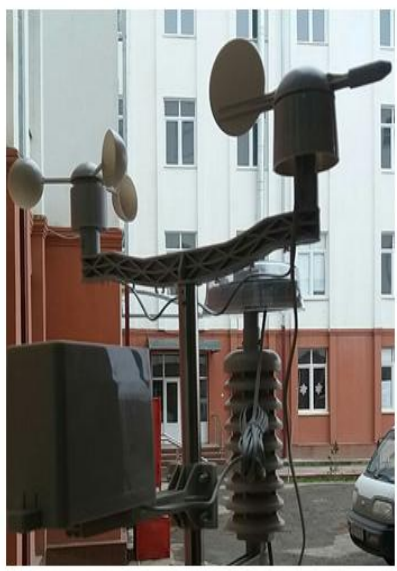

a)

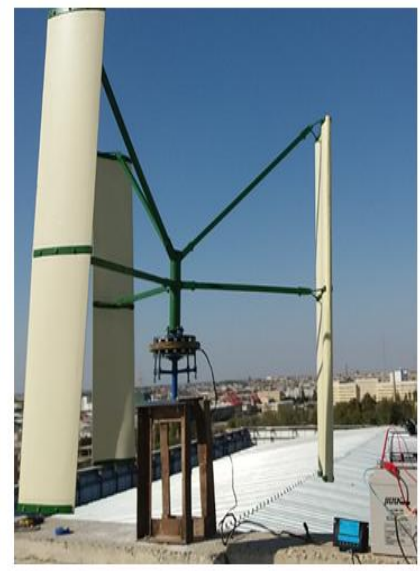

b)
Fig.5. (a) weather station of "MISOL" type, (b)- wind power plant

Sources consistently work or in the mode of accumulation of mechanical energy, or generation of electrical energy. As mechanical energy comes from alternative sources, the energy in the elastic elements of the machine gradually accumulates in the form of potential energy. Regulation of the power flow of the accumulated energy at the flow rate ensures the generation of alternating current electric power with a constant frequency and amplitude of sinusoidal voltage. This allows getting alternating current within the standard indicators of voltage quality.

Improving energy efficiency in industrial facilities is a difficult complex task and depends on multiple factors, such as production technology, efficiency of energy consumers, the quality of energy supplied, the reliability and level of automation of the power supply system, diversification of energy sources, information and analytical support for the rational control of the enterprise's energy etc. Thus, the task of improving the energy efficiency of an enterprise comes to the task of identifying indicators characterizing the efficiency of the electricity source, the power supply system (PSS) and the enterprise's consumers, which directly or indirectly affect the energy efficiency of the enterprise and summarizing them in order of importance relative to a single indicator of energy efficiency.

If the consumer is powered by the power system, the definition of the electrical efficiency of the facility usually does not take into account the energy efficiency of the source of electrical energy, which is the main source of environmental pollution. In order to stimulate the development of "clean" energy, it is necessary to hold responsibility for environmental pollution to those who not only generates, but also those who use "non-clean" electricity. Electricity consumers should compensate for the costs of environmental protection, taking into account the share of participation in pollution (consumed electricity). An enterprise that rejects traditional energy sources and that uses "clean" sources of electricity should be exempted from these additional charges. Therefore, when determining the electrical efficiency of an enterprise, it is necessary to take into account what type of energy resource and power installation is used to supply consumers with electricity. The electrical efficiency of the object's electrical power source is determined by the efficiency factor, conversion of energy into electricity, as well as using more "clean" sources that provide minimal impact on the environment. This indicator is especially important for "smart grid", in which great attention is paid to the diversification of energy sources and for consumers who use autonomous alternative (renewable) energy sources.

\section{RESULTS}

This article analyzes wind speed data and wind energy potential analysis in Bukhara. The statistical analysis of the wind speed and direction of the eight-year (2011-2018) data at $10 \mathrm{~m}$ height was statistically analyzed. Average wind speed is $3.57 \mathrm{~m} / \mathrm{s}$ per year (figure 6).

Figure 7 illustrates the wind direction (wind rose) built in the MatLab environment. The wind direction is more than $20 \%$ northwards.

Table 1 defines the parameters of the wind average speed, standard deviation, Weibull and Relay distribution functions $(\mathrm{k}, \mathrm{c})$, and included in the table. Accordingly, the Weibull distribution parameters are $\mathrm{k}=3.44, \mathrm{c}=3.96 \mathrm{~m} / \mathrm{s}$ and the Rayleigh distributions parameter $\mathrm{k}=2, \mathrm{c}=4.04 \mathrm{~m} / \mathrm{s}$.

The graph of the experimental and intensity functions of the Weibull and Rayleigh distributions in the MatLab environment was used to estimate the characteristics of the wind speed (Figure 8,9). If we analyze these divisional laws, the theoretical function of the Weibull division is more precise than the Rayleigh distribution function, which is based on the experimental function's curvature.

Figure 10 shows the eight-year density wind energy values. The largest wind energy in 2014 is $457.77 \mathrm{kWh} / \mathrm{m}^{2}$.

Figure 11 shows wind velocity values at different heights. These values were determined by static modeling.

In figure 12 and 13, the specific energy and energy values at different heights are determined by extrusion. Wind power and energy density average values at a height of $10 \mathrm{~m}$ are $42.19 \mathrm{~W} / \mathrm{m}^{2}$ and $361.48 \mathrm{kWh} / \mathrm{m}^{2}$. Tensile strength and energy average values at $50 \mathrm{~m}$ are $117.23 \mathrm{~W} / \mathrm{m} 2$ and 1026.96 $\mathrm{kWh} / \mathrm{m} 2$. Tensile strength and energy average values of $100 \mathrm{~m}$ are $192.72 \mathrm{~W} / \mathrm{m}^{2}$ and $1688.59 \mathrm{kWh} / \mathrm{m}^{2}$.

Table 2 summarizes the gross, technical and economic potential of Bukhara region at different heights. Wind energy generates up to 3326.52 billion $\mathrm{kWh} / \mathrm{year}$, technical potential is 66,53 billion $\mathrm{kWh} / \mathrm{year}$, economic potential is 0.33 mill. $\mathrm{kWh} /$ year.

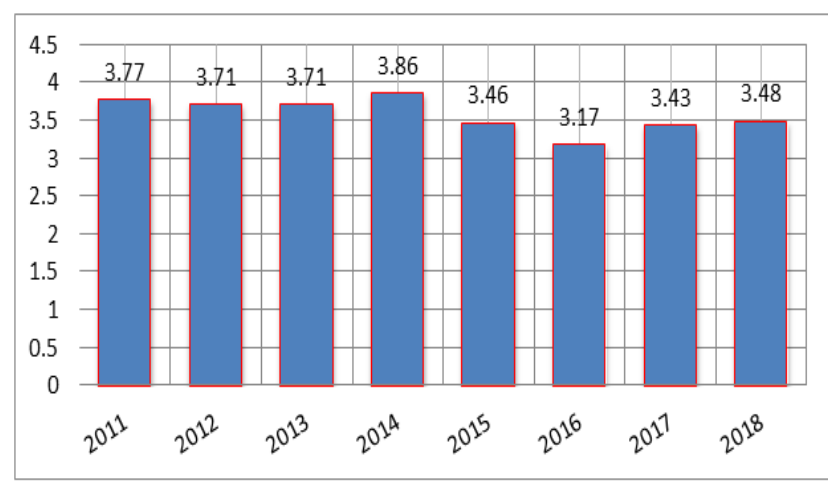

Figure 6. The eight-year measured wind average speed values at a height of $10 \mathrm{~m}$ 


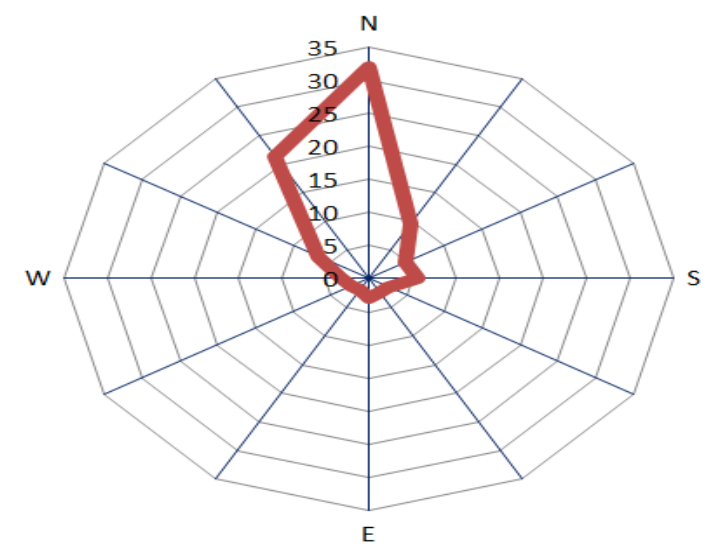

Figure 7. Wind rose (Bukhara region )

\begin{tabular}{|c|c|c|c|c|c|c|c|c|}
\hline \multirow[b]{2}{*}{ Years } & \multirow[b]{2}{*}{$\begin{array}{l}\text { Wind average } \\
\text { speed }\end{array}$} & \multirow[b]{2}{*}{$\begin{array}{l}\text { Standdart } \\
\text { deviation }\end{array}$} & \multicolumn{3}{|c|}{ Verbuill distribution parameteress } & \multicolumn{3}{|c|}{ Rayleigh distribution parameters } \\
\hline & & & $\mathrm{k}$ & $c(m / m)$ & $\begin{array}{l}\text { wind power } \\
\text { density }\left(\mathrm{W} / \mathrm{m}^{2}{ }^{2}\right)\end{array}$ & k & $\mathrm{c}(\mathrm{m} / \mathrm{s})$ & $\begin{array}{l}\text { wind power } \\
\text { densisty }\left(W / \mathrm{WI}^{2}\right)\end{array}$ \\
\hline 2011 & 3,77 & 1,09 & 4,05 & 4,12 & 43,07 & 2 & 4,26 & 63,18 \\
\hline 2012 & 3,71 & 1,09 & 3,85 & 4,10 & 41,25 & 2 & 4,19 & 60,21 \\
\hline 2013 & 3,71 & 1,14 & 3,69 & 4,11 & 42,14 & 2 & 4,19 & 60,21 \\
\hline 2014 & 3,86 & 134 & 3,19 & 4,30 & 52,11 & 2 & 436 & 67,82 \\
\hline 2015 & 3,46 & 135 & 3,07 & 3,85 & 42,11 & 2 & 391 & 48,84 \\
\hline 2016 & 3,17 & 1.20 & 2,97 & 3,54 & 29,79 & 2 & 3,58 & 37,56 \\
\hline 2017 & 3,43 & 120 & 3,33 & 3,81 & 38,93 & 2 & 3,88 & 47,58 \\
\hline 2018 & 3,48 & 1,19 & 3,38 & 3,86 & 40,14 & 2 & 3,93 & 49,69 \\
\hline $\begin{array}{l}\text { Average } \\
\text { values }\end{array}$ & 3,57 & 1,20 & 3,44 & 3,96 & 41,19 & ? & 4,04 & 54,39 \\
\hline
\end{tabular}

Table 1. Wind average speeds, standard deviation, Weibull and Rayleigh distribution function parameters

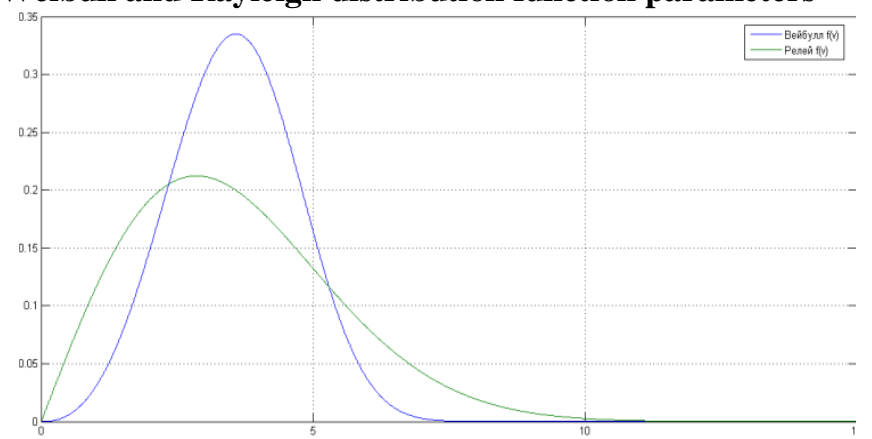

Fig.8. Density functions of Weibull and Rayleigh distributions

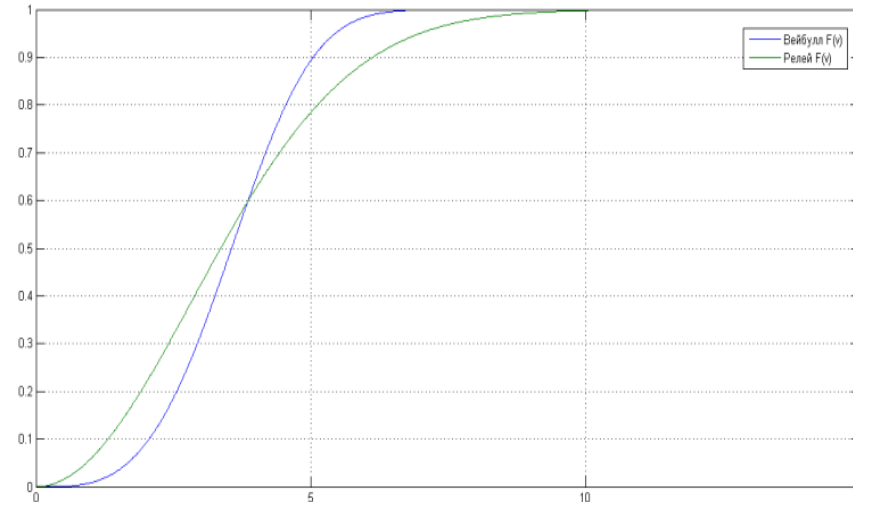

Fig.9. Experimental functions of Weibull and Rayleigh distribution

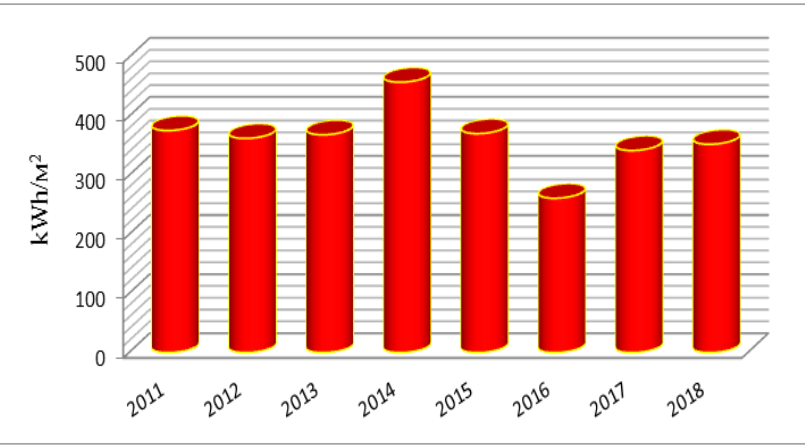

Fig.10. Wind energy density values mentioned in the years

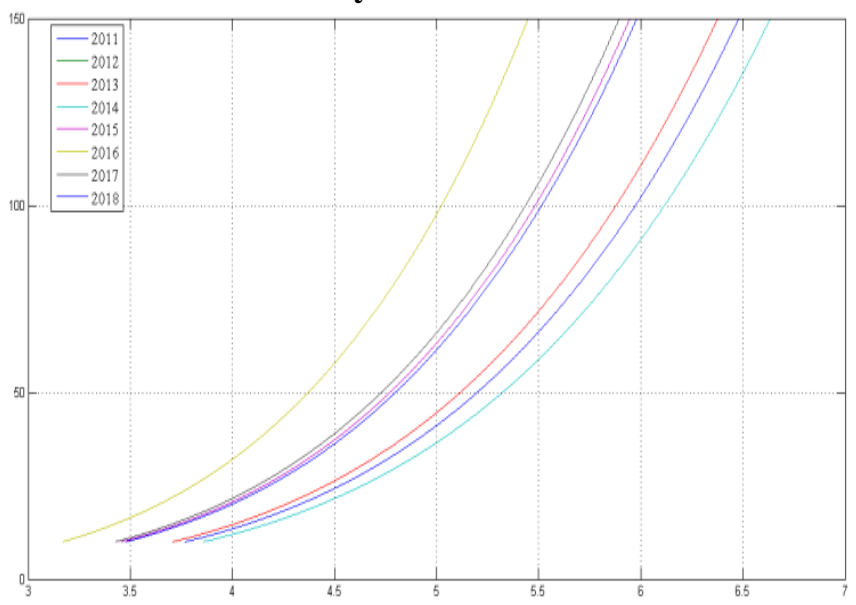

Fig.11. Average wind velocity values at different heights in years

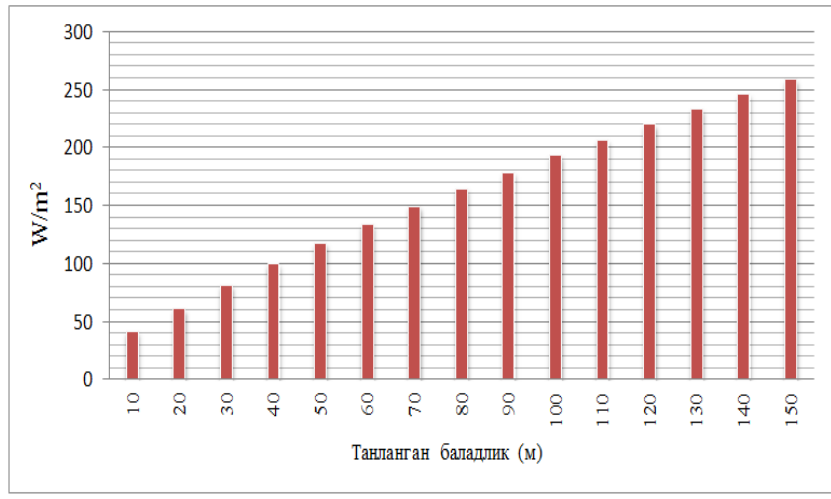

Fig.12. Wind power density values at different heights

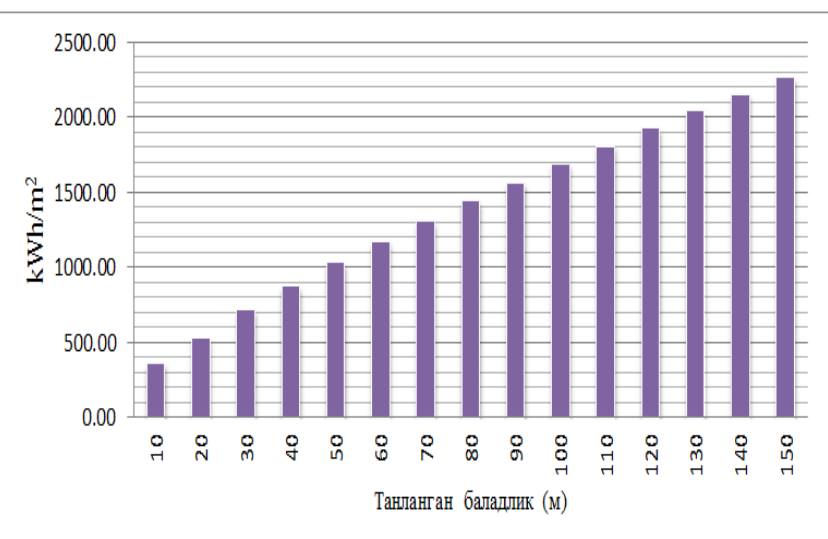

Fig.13. Wind energy density values at different heights

Published By: 


\begin{tabular}{|c|c|c|c|c|}
\hline & \multicolumn{4}{|c|}{ Wind energy potential at the different heights (m) } \\
\cline { 2 - 5 } Wind energy potential & 10 & $\mathbf{5 0}$ & 100 & $\mathbf{1 5 0}$ \\
\hline $\begin{array}{c}\text { Gross potential, } \\
\text { billion kWh/year }\end{array}$ & 712.11 & 2023.11 & 3326.52 & 4456.62 \\
\hline $\begin{array}{c}\text { Technical potential, } \\
\text { billion kWh/year }\end{array}$ & 14.24 & 40.46 & 66.53 & 89.13 \\
\hline $\begin{array}{c}\text { Economical potential, } \\
\text { billion kWh/year }\end{array}$ & 0.07 & 0.2 & 0.33 & 0.45 \\
\hline
\end{tabular}

Table 2. Gross, technical and economic potential of Bukhara region at different heights

\section{CONCLUSION}

1. In evaluation of wind energy potential of Bukhara region, the wind speed and direction data of meteorological station at Bukhara International Airport of the eight-year (2011-2018) were used. Accordingly, the average annual average speed of the eight-year wind is $3.57 \mathrm{~m} / \mathrm{s}$.

2. The direction of the wind direction (wind rose) was constructed and analyzed as the graphic in the MatLab package. The wind blows in the Bukhara region is about $20 \%$ northwards.

3. The two-parameter Weibull and Rayleigh distribution functions were used to evaluate wind power potential. The principal $\mathrm{k}$ and $\mathrm{c}$ parameters of the distribution function (at a height of $10 \mathrm{~m}$ ) were detected. The values determined in the Weibull distribution were 3.44 , $3.96 \mathrm{~m} \mathrm{/} \mathrm{s}$, and the values determined in the Rayleigh distribution were 2 and $4.04 \mathrm{~m} / \mathrm{s}$.

4. The empirical and density functions of the distribution have been constructed to estimate the potential energy potential of the solar energy. The Weibull distribution function was found to have high accuracy in evaluating the potential for wind energy.

5. Wind energy potentials at different heights were evaluated using the Weibull distribution function (20112018). Accordingly, the density power values of the $10 \mathrm{~m}$ height wind as $41.19 \mathrm{~W} / \mathrm{m} 2$, at $50 \mathrm{~m}$ height $117.23 \mathrm{~W} / \mathrm{m} 2$, at $100 \mathrm{~m} 192.76 \mathrm{~W} / \mathrm{m} 2$, at $150 \mathrm{~m} 258.25 \mathrm{~W} / \mathrm{m} 2$ was identified by way of extrapolation

6. The statistical analysis of the eight-year wind speed data (2011-2018) assessed the annual gross, technical and economic potential of the region. Gross potential at $50 \mathrm{~m}$ high reaching 2023.11 billion. $\mathrm{kWh} / \mathrm{m} 2$, the technical potential is 40.46 billion $\mathrm{kWh} / \mathrm{m} 2$, economic potential is 0.2 mln. $\mathrm{kW} \mathrm{h} / \mathrm{m} 2$.

7. When using photovoltaic solar panels (coefficient of efficiency is $18 \%$ ) in the Bukhara region, the technical potential of the region is $41 \mathrm{TWh} /$ year and the technical potential of solar energy, i.e. collector (coefficient of efficiency is $80 \%$ ) is $184 \mathrm{TWh} /$ year.

8. It was found that the use of various alternative energy sources to increase the reliability of electricity supply was a major factor. Because it is possible to achieve a different stream of energy through low or non-current energy flows. By this means, consumers' electricity supply can lead to better consumption and more energy.

9. Increased power supply to consumers by using wind and solar energy has proven to be particularly effective for small-scale consumers in remote areas. Because increasing the reliability of power supply by using wind and solar energy for such consumers can lead to economy of welding, posts and other equipment needed for power supply.

10. The use of wind and solar energy in irrigation systems in remote areas has been a major factor in the supply of electricity. This ensures uninterrupted power supply during irrigation and leads to the development of more productive crops due to an efficient irrigation system.

\section{REFERENCES}

1. https://www.airvisual.com/world-air-quality-ranking

2. B. Eshchanov, M. Stultjes, R. Eshchanov, S. Salaev. "Potential of Renewable Energy Sources in Uzbekistan", Journal of Knowledge Management, Economics and Information Technology, 1 (2011), pp.1-17

3. N. Sadullayev, A. Safarov, Sh. Nematov. "Analysis of wind energy potential in using Weibull distribution in Bukhara region Uzbekistan”, IJARSET, 1 (2019) pp.7846-7853

4. S.V. Kiseleva, Yu.G. Kolomiets, O.S. Popel, "Assessment of solar energy resources in Central Asia", Applied Solar Energy, V-51, I-3, pp.214-218, 2015

5. R.A. Zakhidov, M.V. Kremkov, "The wind power potential of Uzbekistan", Applied Solar Energy, V-51, I4, pp. 336-337, 2015

6. J.N Touafio, S. Melenguiza, S.A Oumarou, Y. Kazet, "Statistical analysis and elaboration of the wind potential map of the city of Bangui (Central African Republic)", Renewable Energy Focus, 29 (2019), pp.1-13

7. B. Eshchanov, A. Abylkasymova, F. Aminjonov, D. Maldokanov, I. Overland, R. Vakulchuk. "Wind Power Potential of the Central Asian Countries", Central Asia Regional Review 17 (2019) pp.1-7

8. B.N Prashanth, R. Pramod, G.B Veeresh Kumar, "Design and Development of Hybrid Wind and Solar Energy System for Power Generation", Materials today: proceedings, 5(2018), pp. 11415-11422

9. C. Ozay, M. Soner. "Statistical analysis of wind speed using two-parametr Weibull distribution in Alacati region", Energy conversion and management, 12 (2016) pp. $49-54$

10. T. Ouarda, Ch. Charron, "On the mixture of wind speed distribution in a Nordic region", Energy Conversion and Management, 174 (2018) pp.33-44

11. P. Vais, "Two and three-parametr Weibull distribution in available wind power analysis", Renewable Energy, 103 (2017) pp.15-29.

12. S. Ahmed, H. Mahammed. "A Statistical Analysis of Wind Power Density Based on the Weibull and Ralyeigh models of "Penjwen Region" Sulaimani/ Iraq. Jordan Journal of Mechanical and Industrial Engineering. 6 (2012) 135-140.

13. G. Johnson, "Wind Energy Systems", 2006. pp. 2-16...243

14. D. Hui Ko, Sh. Taek Jeong, Y. Chil Kim. "Assesment of wind energy for small-scale wind power in Chuuk State, [26] Micronesia", Renewable and Sustainable Energy Reviews, 52 (2015) pp. 613-622

15. M. El-Sharkawi. "Wind energy an introduction". 2016. pp. $43-57$

16. A. Celik, "A statistical analysis of wind power density based on the Weibull and Rayleigh models at the southern region of Turkey", Renewable energy, 29 (2004) pp. 593-604

17. M. Soulouknga, S. Doka, N. Revanna, N. Djongyang, T. Kofane. "Analysis of wind speed data and wind energy 
potential in Faya-Largeau, Chad, using Weibull distribution", Renewable energy, 121 (2018) pp.1-8.

18. P. Chaurasiya., S. Ahmed, W. Varudkar, "Stady of different parametrs estimation metods of Weibull distribution to determine wind power density using ground based Dopller SODAR instrument", Alexandra Engineering Journal, 80 (2017) pp. 34-40

19. B. Berlin, "Modeling the Weibull shape parameter to improve estimates of the annual wind energy potential in Sweden". 2018. pp. 19-20

20. V. Elistratov, A. Ramadan,"Energy potential assessment of solar and wind resources in Syria", Journal of Applied Engineering Science, 16 (2018) pp. 208-216 